\title{
Modelo de Análise Didática dos Erros: um guia para analisar e tratar erros referentes à função polinomial do $2^{\circ}$ grau
}

\author{
Model Didactic Analysis of Errors: a guide to analyze and treat errors relating to the \\ polynomial function of 2 nd degree
}

\author{
Maria Luisa Ramos \\ mlperdigao@yahoo.com.br
}

Edda Curi

edda.curi@gmail.com

\begin{abstract}
Resumo
Neste artigo são apresentados resultados parciais de uma investigação de doutorado que tem como objetivo identificar erros cometidos por alunos do $1^{\circ}$ ano do Ensino Médio no conteúdo de função. Para isso, nos embasamos em referenciais teóricos que dão um tratamento didático ao erro. Como metodologia de pesquisa foi utilizado o Modelo de Análise Didática dos Erros - MADE - composto por categorias que fazem parte de três momentos de um procedimento sistêmico: entrada, organização e execução. Participaram da pesquisa 37 alunos do curso técnico integrado de uma escola pública de Minas Gerais. Apresentamos aqui duas questões referentes ao conteúdo de função polinomial do $2^{\circ}$ grau retiradas do teste aplicado aos alunos durante a investigação. Com o resultado, foi possível perceber que os alunos apresentaram dificuldades oriundas do Ensino Fundamental, além de dificuldades conceituais sobre função polinomial do $2^{\circ}$ grau.
\end{abstract}

Palavras-chave: Dificuldade. Análise didática dos erros. Função polinomial do $2^{\circ}$ grau.

\begin{abstract}
In this paper preliminary results of an investigation of doctorate that aims to identify errors made by students in the 1st year of high school in the content function are presented. For this, we rely on theoretical frameworks that give a didactic treatment of error. As research methodology of the Model Curriculum Analysis of Errors MADE - composed of categories that are part of three moments of a systemic procedure was used: entry, organization and implementation. 37 students of integrated public school technical course of Minas Gerais participated in the research. Here are two questions regarding the contents of polynomial function of 2 nd degree removed from the test administered to students during the investigation. With the result, it was revealed that students had difficulties coming from the elementary school, as well as conceptual difficulties about polynomial function of 2 nd degree.
\end{abstract}

Keywords: Difficulty. Didactic analysis of errors. Polynomial function of 2nd degree.

\section{Introdução}

Várias são as contribuições que os indícios do erro oferecem para o professor: informam que o aluno que se enganou necessita de ajuda; oferecem pistas sobre o raciocínio do aluno; 
proporcionam mais informações sobre os processos utilizados pelo aluno; indicam novas direções a serem dadas nas estratégias didáticas e nos métodos de ensino e demonstram a melhoria de desempenho do aluno em relação à turma. Essas contribuições são citadas por diversos autores que investigam a possibilidade de se dar um tratamento didático ao erro.

Um ponto que deve ser destacado é a visão que o aluno tem do seu erro. Como o aluno vê o erro? Ele é visto pelo aluno como algo negativo, que lhe gera culpa e angústia. De La Torre (2007) cita que "Poucos estudantes vêem no equívoco um modo de aprender. Mais ainda, consideram justa a punição, o que os incapacita para reagir a isso como uma injustiça” (p. 90).

Citando Socas (1997), Lupiáñez (2013) afirma que o erro é uma manifestação visível de uma dificuldade. $\mathrm{O}$ autor menciona ainda que as dificuldades de aprendizagem em matemática têm origens distintas e reconhece que duas dessas causas estão na complexidade do objeto matemático e nos próprios processos da atividade matemática.

Sendo assim, o erro pode indicar, tanto para o aluno quanto para o professor, que existem falhas em algo que foi ensinado. Se o erro for visto por ambos de forma positiva e o professor analisar o que o erro está indicando, poderá intervir positivamente na aprendizagem de seu aluno.

Além de contribuir com o aprendizado do aluno, a análise de erros possibilita melhorias na didática do professor. Aderente às ideias citadas, apresentamos neste artigo, por meio de um modelo de análise didática dos erros, os erros cometidos por 37 alunos do $1^{\circ}$ ano do Ensino Médio, em duas questões de Matemática sobre o conteúdo de funções polinomiais do $2^{\circ}$ grau, que fazem parte de uma investigação maior realizada pelas autoras.

\section{Fundamentação Teórica}

A análise dos erros em produção escrita é uma proposta de estratégia didática indicada por diversos referenciais teóricos. Apesar dos erros variarem de acordo com cada disciplina e conteúdo, o professor pode utilizar esse tipo de estratégia didática em diversas disciplinas e em diferentes níveis de ensino. Exemplos disso são citados em Ramos (2013) e Ramos e Curi (2013) em que as autoras apresentam análise de erros realizada em produções escritas de alunos, na disciplina de Sistemas Digitais, envolvendo circuitos lógicos.

Confirmando a utilização da análise de erros como estratégia didática em diversas disciplinas,

De La Torre (2007) cita que, 
Entre as didáticas especiais que mais atenção prestaram à análise dos erros estão o estudo das línguas (em particular a segunda língua) e a matemática. Enquanto as primeiras focalizam sua atenção nos erros de execução, a matemática atende aos erros de raciocínio, de compreensão e de organização biológica da informação (DE LA TORRE, 2007, p. 128).

Ainda segundo De La Torre (2007), os erros cometidos nas atividades de matemática concentram-se nas falhas de compreensão e no processo lógico adotado. Dessa forma, a partir da análise de erros, o professor pode modificar sua estratégia didática utilizando metodologia mais adequada às necessidades dos alunos.

Figura 1 - Modelo de Análise Didática dos Erros - MADE

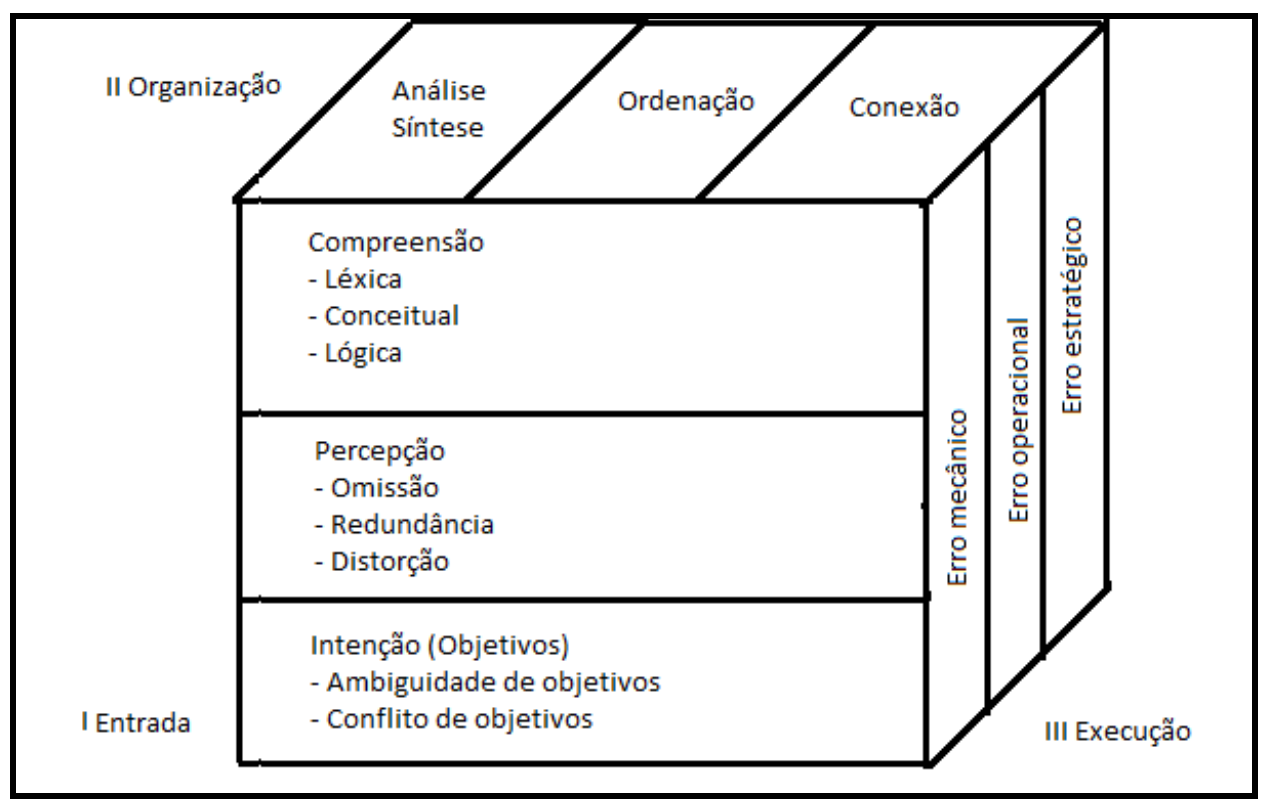

Fonte: DE LA TORRE, 2007, p. 108.

Para isso, De La Torre (2007) propõe um Modelo de Análise Didática dos Erros - MADE, conforme Figura 1, por meio do qual poderão ser “[...] recolhidas as principais dimensões e categorias do erro, que podem servir de guia tanto na investigação como para sua análise e seu tratamento didático" (p. 108). O MADE é composto de três momentos, como qualquer procedimento sistêmico: Entrada, Organização (processamento) e Execução (saída).

Descreveremos na sequência, de forma detalhada, como o erro pode ser utilizado e analisado no sistema educacional por meio dos três momentos do processo apresentado na Figura 1.

* Momento de Entrada é, provavelmente, o instante que pode apresentar o maior número de erros, pois ocorrem problemas de interpretação entre os dados de entrada (informações inadequadas ou insuficientes) em algum desses três planos - intenção, percepção e compreensão - e o que precisa ser exibido na saída após o processamento. 
No plano das intenções, De La Torre (2007) abrange três situações do erro, sendo a primeira caracterizada pela indefinição de metas ou falta de clareza, ou seja, o aluno não compreende o que está sendo solicitado pelo professor. Por outro lado, o professor não deixa claro o que ele quer que seja realizado e nem para que serve a atividade.

O autor afirma que a segunda situação ocorre quando há incompreensão ou confusão do objetivo ou da intenção. Os erros cometidos nessa fase acontecem pela falta de maturidade do aluno em relação ao tipo de objetivo apresentado em uma atividade. Para que não ocorram erros desse tipo, os objetivos de uma atividade devem ser traçados pelos professores de acordo com o nível de conhecimento do aluno.

Os erros cometidos na terceira situação, segundo o autor, são provenientes do conflito de objetivos ou do desvio da meta fixada. Esse tipo de erro ocorre quando o aluno vai além daquilo que foi solicitado, mas desviando do caminho correto a ser seguido, ou quando se interessa por uma parte do assunto e se esquece de desenvolver o restante da questão.

De La Torre (2007) menciona que os erros correspondentes à categoria das intenções podem ser facilmente evitados, pois, na maioria das vezes, o próprio professor é o principal responsável pela indução do aluno ao erro.

Ainda no momento de "Entrada", De La Torre (2007) afirma que os erros cometidos pela inadequada percepção da informação são em sua maioria de responsabilidade da metodologia docente ou da capacidade discente. Três são as modalidades da categoria de percepção: erros de omissão, de redundância e de distorção. Segundo o autor, os erros de omissão acontecem por sobrecarga de informação, isto é, o aluno possui muitas informações, mas não consegue sintetizá-las para que sejam usadas em uma determinada situação; por distração, devido a imaturidade cognitiva e, por último, pela insuficiente percepção ou análise da tarefa, isto é, quando passam despercebidos pelo aluno alguns detalhes que deveriam ser levados em consideração ao responder a questão.

$\mathrm{O}$ autor revela ainda que alguns alunos cometem erros devido à redundância de informação. A repetição costuma ajudar alguns, mas atrapalha outros. Os erros de distorção normalmente acontecem quando a informação é pouco clara, confusa, ambígua e algumas vezes, estranha aos interesses cognitivos. Às vezes, o aluno sente que sabe, mas distorce o que não sabe, pelo fato de simplificar tanto os dados que acaba alterando o significado deles.

A última modalidade dessa categoria, de acordo com De La Torre (2007), são os erros na compreensão léxica, conceitual ou lógica. São erros que acontecem geralmente pela falta de 
compreensão da tarefa. Ao compreender um conteúdo o aluno deve ser capaz de expressá-lo com sua própria linguagem; quando isso não é possível, o aluno acaba cometendo erros dessa natureza.

* Organização dos Dados é o próximo passo a ser realizado, após a obtenção das informações de entrada. É nesse momento que os processos cognitivos do aluno são colocados em prática. Esses tipos de erros estão associados à análise e síntese da informação obtida, à ordenação dessa informação e à sua conexão com o conhecimento. Segundo De La Torre (2007), "Os erros de organização ocorrem quando o sujeito trata de mudar a informação de que dispõe para dar com a resposta que lhe é pedida" (p. 118). O aluno pode cometer erros nas diversas etapas citadas anteriormente ao organizar as informações. Ele pode errar ao analisar e sintetizar as informações de entrada ou ao ordená-las em sequência ou ao fazer conexões dessas informações com o conhecimento que possui.

* Erros de Execução são cometidos com mais frequência por alunos que gostam de arriscar novos caminhos na solução de um problema, sendo muito comum a ocorrência com alunos hiperativos. Esses erros são identificados por De La Torre (2007) como erros mecânicos ou lapsos, e acontecem quando há uma troca de sinal, ou de letras e até mesmo de palavras; os erros operacionais e de distração, tem o nervosismo como uma das causas frequentes e, finalmente, os erros estratégicos são erros de procedimento, ou seja, acontecem quando o aluno comete um equívoco na utilização de uma estratégia adequada ao resolver um problema.

Com o uso do MADE, é possível que o professor identifique a causa do erro e o retifique com o intuito de não deixá-lo se tornar um erro recorrente. De La Torre (2007), ainda cita que o modelo pode ser utilizado por professores desde o Ensino Infantil, a partir do aprendizado da leitura-escrita e das operações aritméticas, até o Ensino Superior. O autor também afirma que, embora o "MADE tenha uma primeira intenção descritiva, não há dúvida de que pode nos ser útil em nível explicativo, preditivo e corretivo" (p. 109).

\section{Metodologia da pesquisa}

As duas questões aqui analisadas são um recorte de uma investigação realizada com 37 alunos do $1^{\circ}$ ano do curso técnico de nível médio modalidade integrada de uma escola pública de 
Minas Gerais. Neste artigo, as questões analisadas foram as referentes ao conteúdo de função polinomial do $2^{\circ}$ grau enumeradas como 7 e 10 .

Para realização desta investigação utilizamos da análise de erros (CURY, 2013) executada em três etapas conforme descrito a seguir.

$\mathrm{Na}$ primeira etapa, cada aluno foi identificado com a letra $\mathrm{A}$ seguida de um número. Posteriormente, as resoluções iguais de cada questão foram agrupadas, excluindo-se aquelas que não apresentavam resolução. Dessa forma, "Esse conjunto de questões organizadas forma o corpus, sobre o qual o investigador se debruça para realizar a análise das respostas." (CURY, 2013. p. 6, grifo no original), tornando-se mais fácil a leitura das respostas dadas.

Para correção das questões foram criados quatro códigos de classificação, segundo Leivas e Cury (2010) e Cury (2013). Cada um desses códigos recebeu o mesmo número utilizado na correção de questões do Programa Internacional sobre Avaliação de Estudantes - PISA. Eles foram denominados como: resposta correta - Código 2; resposta parcialmente correta Código 1; resposta incorreta - Código 0 e ausência de resposta - Código 9.

Na segunda etapa, trabalhamos com "o processo de unitarização e classificação das respostas parcialmente corretas ou incorretas" (CURY, 2013, p. 6). Para as respostas semelhantes, definimos as categorias de erro. Para identificação dessas categorias, dentro dos códigos de respostas parcialmente corretas (código 1) e incorretas (código 0), utilizamos o MADE (DE LA TORRE, 2007).

Na última etapa, utilizamos de exemplos retirados do próprio corpus para descrevermos sobre os erros identificados.

Acreditamos que, dessa maneira, conseguimos apresentar de forma mais clara as respostas dadas pelos alunos em cada questão, além de analisar cada erro cometido dentro de suas categorias específicas.

\section{Apresentação e análise dos dados}

No Quadro 1 estão apresentados o número de respostas por classificação e o valor percentual correspondente nas resoluções apresentadas pelos alunos sobre o conteúdo de função polinomial do $2^{\circ}$ grau para cada questão analisada. 
Quadro 1: Distribuição de Respostas por Classificação

\begin{tabular}{|c|c|c|c|c|}
\hline \multirow{2}{*}{ Classificação } & \multicolumn{4}{|c|}{ Questões } \\
\cline { 2 - 5 } & & $\%$ & $N^{\mathrm{o}}$ & $\%$ \\
\cline { 2 - 5 } & $\mathrm{N}^{\mathrm{o}}$ & $19 \%$ & 8 & $21,5 \%$ \\
\hline Correta & 7 & $38 \%$ & 7 & $19 \%$ \\
\hline Parcialmente Correta & 14 & $38 \%$ & 14 & $38 \%$ \\
\hline Incorreta & 14 & $5 \%$ & 8 & $21,5 \%$ \\
\hline Em Branco & 2 & & $8 \%$ \\
\hline
\end{tabular}

Fonte: Elaborado pela pesquisadora

Foi realizada uma análise das respostas para cada questão e esse procedimento é essencial, pois segundo Lima e Buriasco (2008), "Nem o acerto é garantia suprema de um conhecimento, nem o erro indica a ausência total dele.” (p. 82).

Na questão 7 foi solicitado: Em uma empresa que vende tratores, o lucro total L em função da quantidade $q$ de tratores vendidos pode ser obtido pela expressão $L(q)=-32-2(q 2$ - 10q). Nestas condições, quais os valores de q para que a empresa trabalhe sempre com lucro positivo?

$\mathrm{Na} 7^{\mathrm{a}}$ questão, o nosso objetivo foi verificar se, ao analisar o enunciado de uma situaçãoproblema sobre função polinomial do $2^{\circ}$ grau, o aluno consegue identificar e esquematizar o que estava sendo solicitado. Também foi possível observar se o aluno consegue achar os zeros da função, além de analisar sua concavidade e definir o intervalo de resposta.

A Figura 2 exibe a resposta correta dada por A15, que foi considerada como resposta padrão para realização da análise. É importante definir uma resposta padrão a partir das respostas apresentadas pelos alunos, pois não estaremos "julgando os erros de nossos alunos a partir de nossas estruturas mentais" (DE LA TORRE, 2007, p. 108).

Figura 2 - Resposta Apresentada por A15

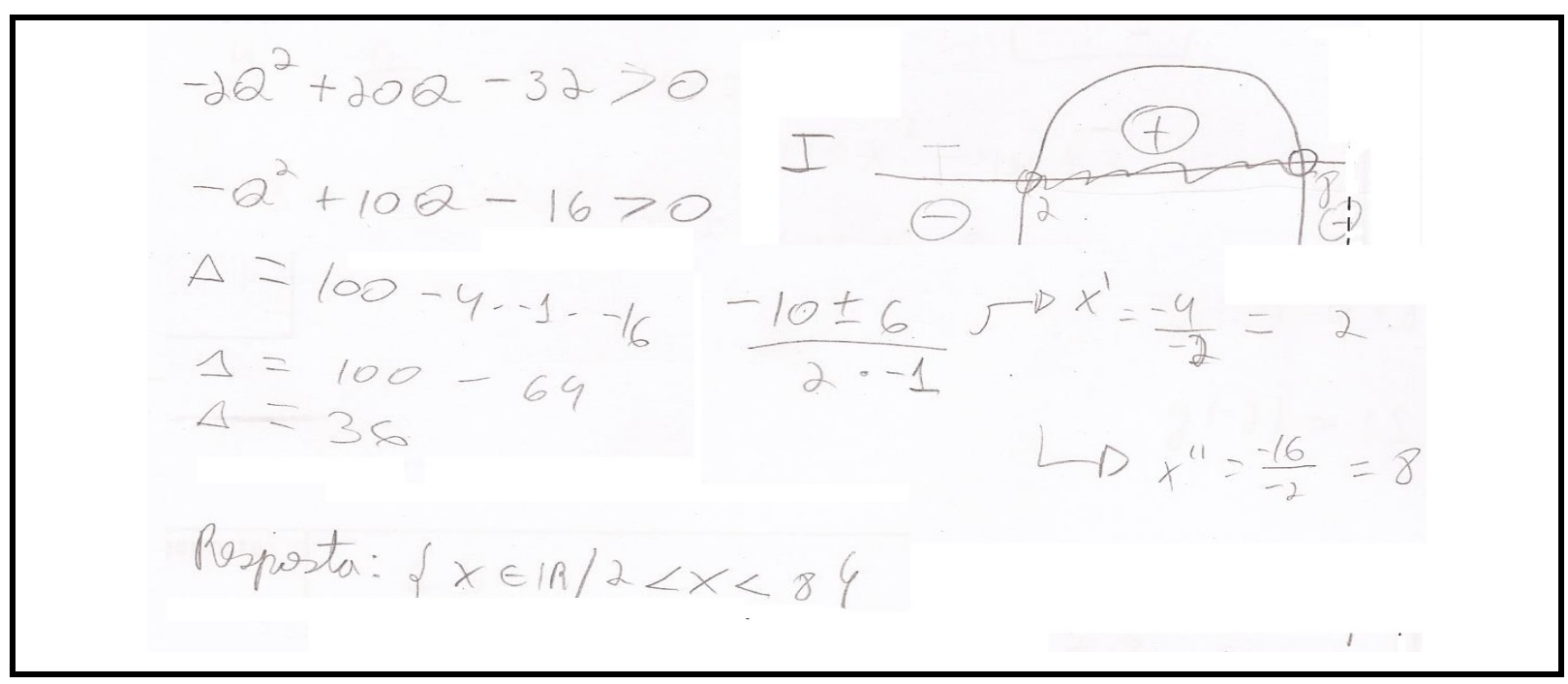

Fonte: Teste Investigativo, questão 7. 
A15 inicia a resolução a partir da condição citada no enunciado da questão, o qual descreve que a empresa deve sempre trabalhar com lucro positivo. Partindo disso, ele encontra os zeros da função, esboça a parábola e realiza o estudo de sinais, finalizando com a apresentação da solução do problema.

Os erros cometidos pelos alunos na questão 7 decorreram de diversos fatores, sendo a maioria deles erros de execução categorizados como Erros Operacionais de acordo com o MADE (DE LA TORRE, 2007). Grande parte dos erros foi consequência do desrespeito às prioridades operacionais da aritmética, nesse caso, a aplicação da propriedade distributiva. A Figura 3 exibe dois erros desse tipo. Tanto A25 quanto A6 efetuaram operações entre os números 32 e 2 antes de aplicarem a propriedade distributiva. Outros alunos ao aplicarem a distributiva encontraram $L(q)=-32-2 q^{2}-20 q$ ao invés de $L(q)=-32-2 q^{2}+20 q$. Assim, acharam os zeros da função iguais a -2 e -8 .

Figura 3 - Erros Cometidos por A25 e A6, respectivamente.

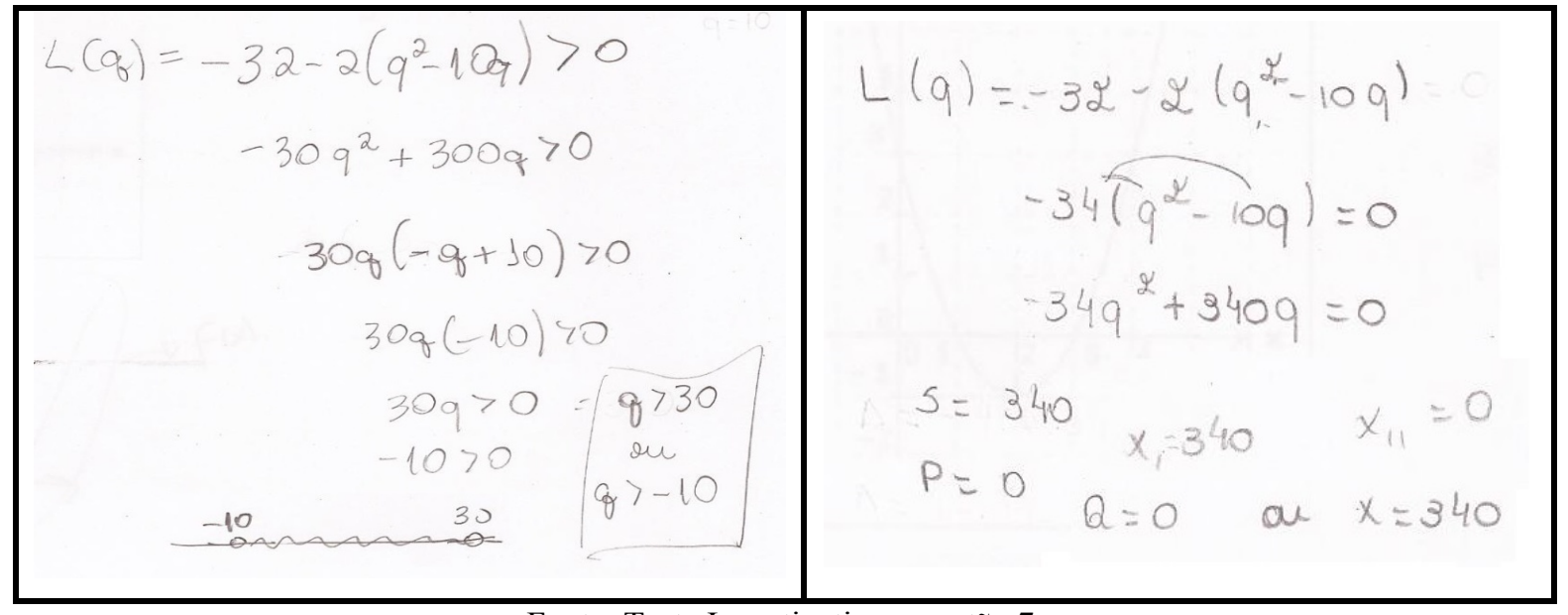

Fonte: Teste Investigativo, questão 7.

Também dentro da categoria de Erros Operacionais, os alunos apresentaram dificuldades para encontrar os zeros da função e de escrever a resposta encontrada na resolução da questão, pois não conseguiram realizar de forma correta o estudo de sinais. A Figura 4 apresenta a resolução dada por A7. Apesar de apontar que a solução da questão é para todo $\mathrm{L}>0$, ele não levou em consideração essa condição no desenvolvimento do problema. Devido a isso, A7 encontrou os zeros da função, mas identificou incorretamente a concavidade da parábola e a solução da questão.

Nas resoluções apresentadas foi possível observar também os erros decorrentes de "distração" que, segundo De La Torre (2007), também são categorizados como Erros Operacionais. Um exemplo disso está na resolução apresentada por A20, quando ao copiar um número, se 
confundiu e escreveu outro. A20 errou escrevendo -2 ao invés de $\mathbf{- 2 0}$ : $\left(\left(-20 \pm \sqrt{\left.20^{2}-4 \cdot(-2) \cdot(-32)\right)} / 2 \cdot(-2)\right) ;((-2 \pm \sqrt{400+8(-32))} /(-4))\right.$. Erros por desatenção também foram observados no trabalho apresentado por Lima e Buriasco (2008). Pinto (2000) cita que esse tipo de engano não deve ser considerado como erro, pois o próprio aluno, ao analisar a sua resolução, é capaz de identificar e retificar o que errou.

Figura 4 - Respostas Apresentadas por A7.

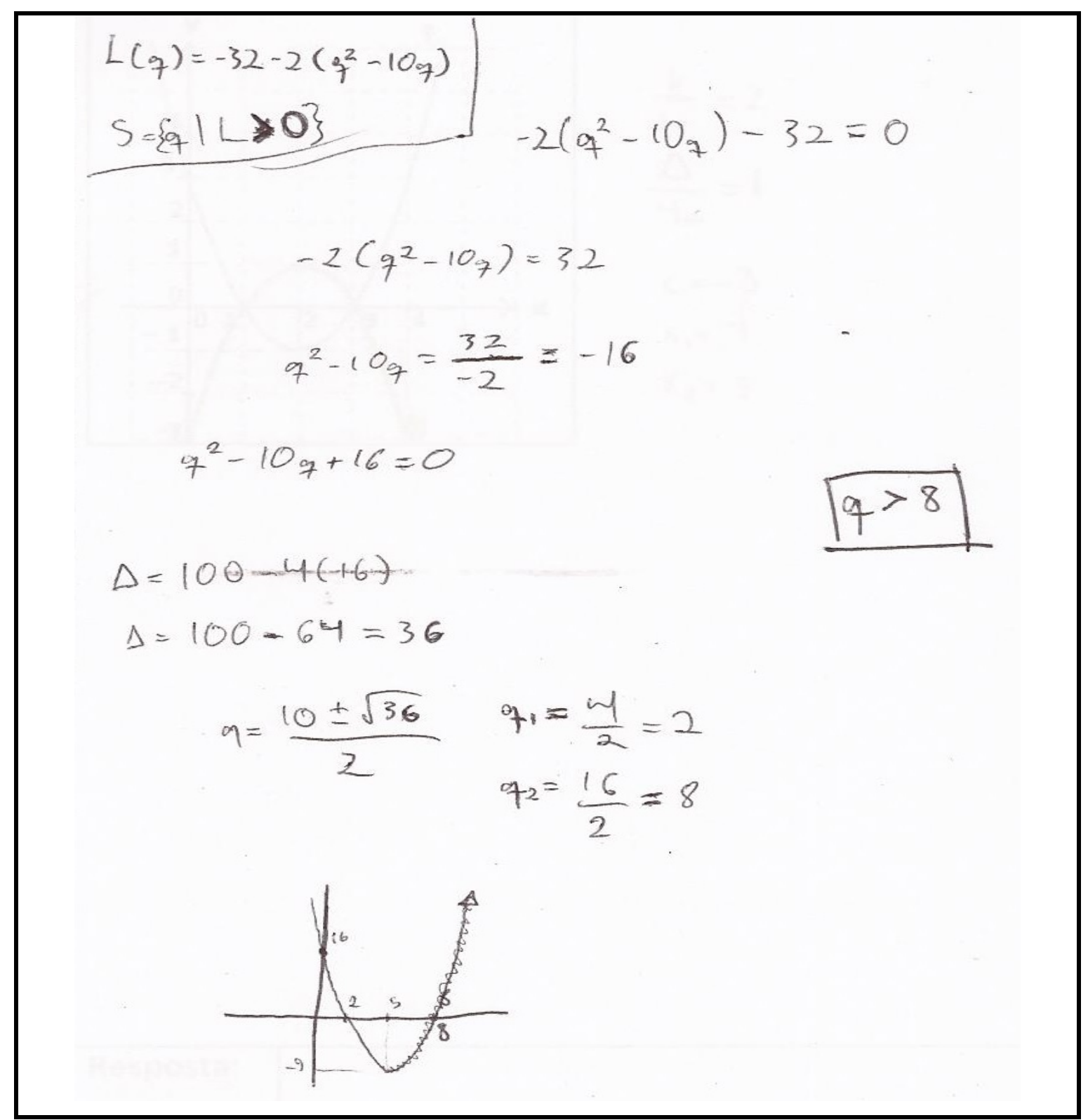

Fonte: Teste Investigativo, questão 7.

A maioria dos alunos não conseguiu identificar o que foi solicitado na questão. Dessa forma, as dificuldades encontradas e os erros cometidos devem ser categorizados, segundo De La Torre (2007), como Erros de Compreensão, ou seja, “A falta de compreensão na linguagem 
não se circunscreve somente à área de linguagem, nós a encontramos em qualquer disciplina, incluindo a matemática." (p. 115). Isso pode ser confirmado quando se observa o número de alunos que acertaram a questão (sete), além das anotações feitas por eles no final de cada questão.

O enunciado da questão 10 foi: Durante uma situação de emergência, o capitão de um barco dispara um sinalizador para avisar a guarda costeira. A trajetória que o sinal luminoso descreve é um arco de parábola. A função que descreve o movimento do sinal luminoso é dada por $h(t)=80 t-5 t^{2}$, sendo h a altura do sinal, em metro, e $t$, o tempo decorrido após o disparo, em segundo. a) Qual é a altura máxima que esse sinal luminoso pode atingir? b) Quantos segundos se passam, após o disparo, até o sinal luminoso atingir a altura máxima?

$\mathrm{Na}$ questão 10, o nosso objetivo foi verificar se o aluno apresenta dificuldades em esquematizar uma situação-problema dentro do conteúdo de função polinomial do $2^{\circ}$ grau. $\mathrm{Na}$ resolução do problema o aluno deveria identificar as variáveis independente e dependente por meio dos zeros ou do ponto máximo da função.

A resolução correta dada por A31 está exibida na Figura 5 e foi considerada como resposta padrão para a análise desta questão. Alguns alunos que acertaram a questão, diferentemente de A31, encontraram a resposta aplicando as fórmulas normalmente utilizadas para se achar o valor máximo de uma função $\left(X_{v}, Y_{v}\right)$.

Figura 5 - Resposta

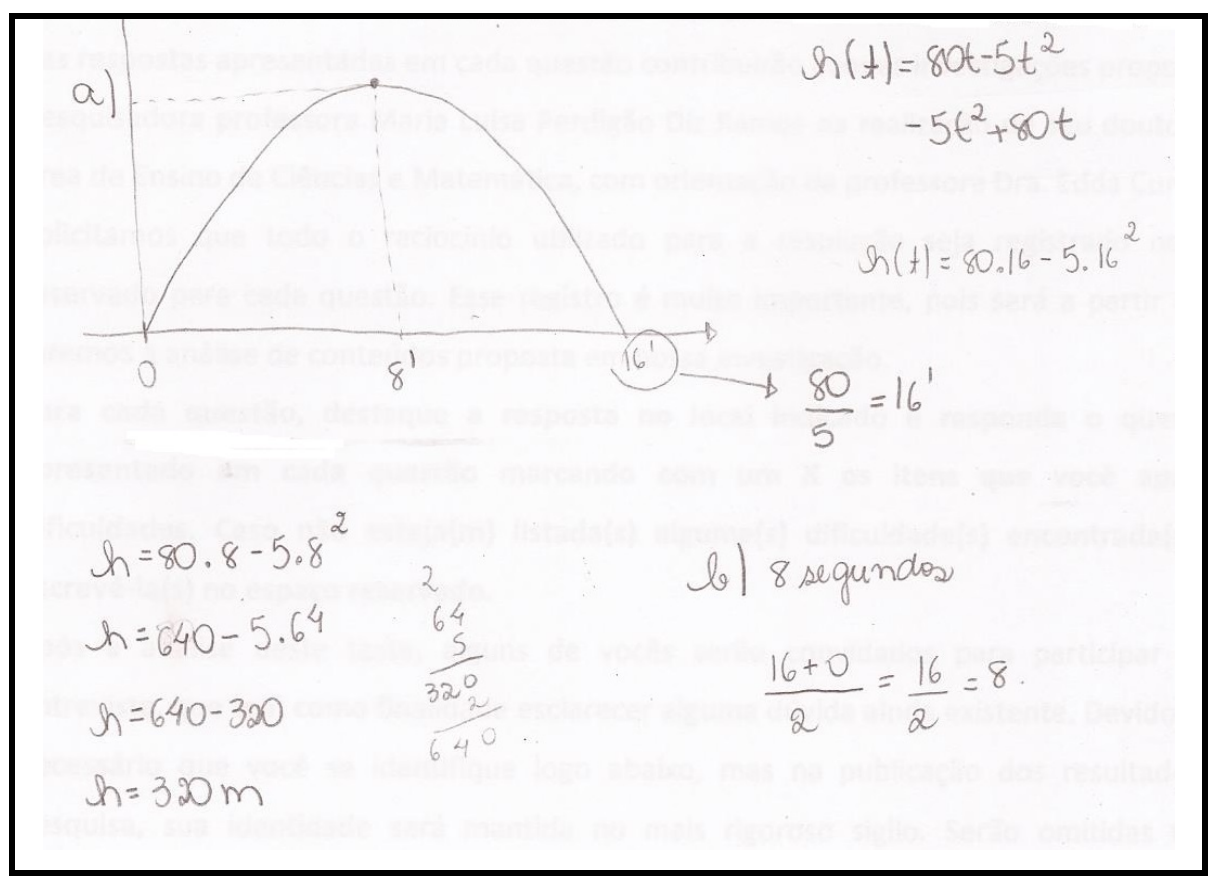

Apresentada por A31

Fonte: Teste Investigativo, questão 10. 
Para resolver a questão, A31 não precisou usar de fórmulas. Ele encontrou os zeros da função polinomial de $2^{\circ}$ grau, traçou a parábola e indicou que o ponto máximo ocorreu na metade do tempo, entre 0 e 16 segundos. Para encontrar a altura máxima, A31 substituiu o valor do tempo (8s) para altura máxima da função e encontrou $h(8)=320 \mathrm{~m}$.

Ao analisar o processo e não apenas o resultado apresentado pelo aluno na resolução da questão, o professor pode verificar as diversas formas de se resolver uma questão e assim, adotar a melhor resolução como resolução padrão junto à turma. A resolução dada por A31 é um exemplo do que foi dito, pois para chegar à resposta, ele fez uso do raciocínio lógico e não da aplicação direta de fórmula.

Figura 6 - Resposta Apresentada por A20

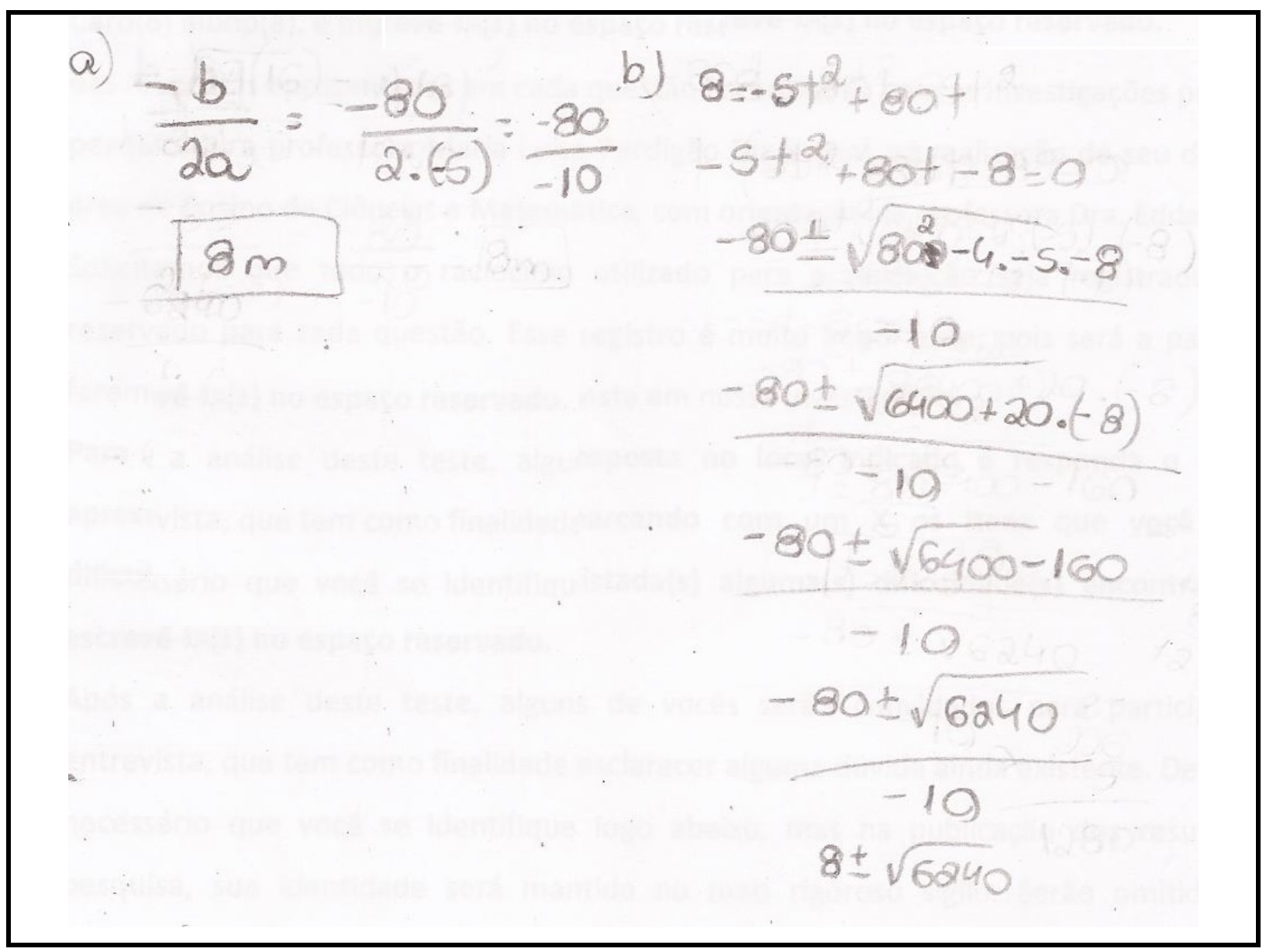

Fonte: Teste Investigativo, questão 10.

Nesta questão, os alunos apresentaram dificuldades e erros correspondentes à compreensão associados às categorias Conceitual e Lógica. Os erros cometidos pelos alunos nessas categorias resultam-se pela não diferenciação entre as variáveis independente e dependente, pela divisão da função por 5 e pela utilização de $t=-1$ por substituição. $O$ erro cometido por A20, que foi o de não conseguir diferenciar as variáveis independente e dependente, está 
mostrado na Figura 6. O aluno encontra o valor de t e cita que esse é o valor da altura máxima. A partir disso, utilizando-se de vários cálculos, tenta por meio de substituição encontrar $\mathrm{t}$, sem chegar a nenhum resultado.

Os erros cometidos por A5 e A19 foram erros de compreensão e podem ser categorizados como Erros de Lógica e Conceitual (FIGURA 7). Tanto A5 quanto A19 dividiram a função original por 5 antes de encontrarem o ponto máximo da função. Devido a isso, o valor da altura máxima também ficou dividido por 5 , portanto, cometeram erro no cálculo dessa altura.

Figura 7 - Resposta Apresentada por A19

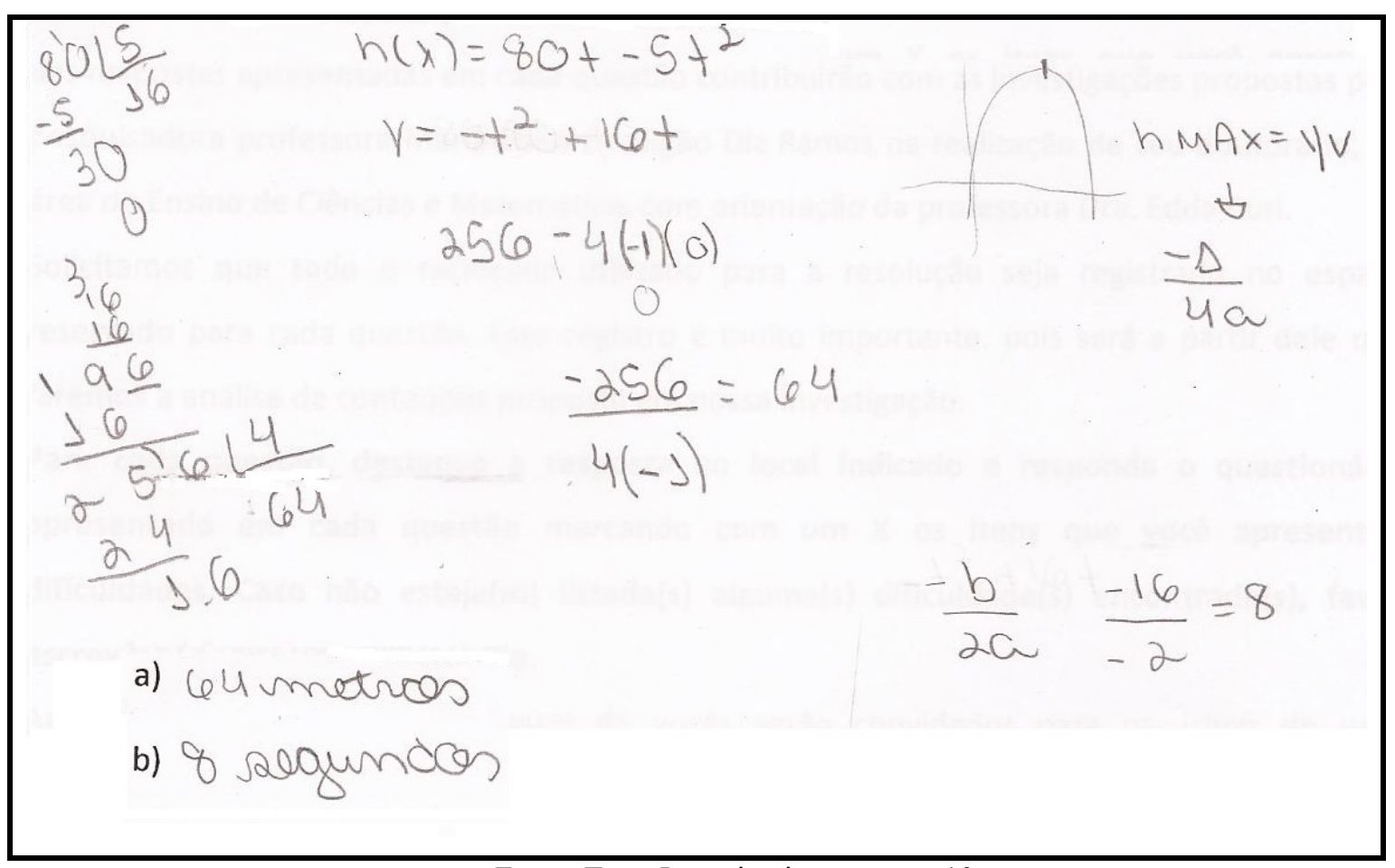

Fonte: Teste Investigativo, questão 10.

Além dos erros citados, outros foram cometidos e categorizados como: Erro de Conexão, pois não conseguiram organizar ou conectar a informação com o resultado; Erros Mecânicos, devido à troca de sinais; Erros Operacionais, quando trocaram o uso das fórmulas de Xv e Yv, além de erros cometidos durante a realização de operações e também por terem considerado c $=1$ no cálculo do $\Delta$. Por fim, Erros Estratégicos, quando do uso de procedimento inapropriado na solução do problema, isto é, acharam o zero da função e o utilizaram para encontrar a variável independente, sem analisar a parábola.

Um dos Erros Operacionais está apresentado na Figura 8. A4 considerou $\mathrm{c}=1$ ao calcular o valor de $\Delta$. Ele também não soube diferenciar a variável independente da variável dependente, apresentando então as respostas invertidas. Assim, a resolução exibida por A4, além de 
apresentar erros que são categorizados por meio do MADE (DE LA TORRE, 2007) como Erro Operacional, também apresentou erros classificados nas categorias Conceitual e de Lógica. A4 ainda cometeu Erros de Conexão, pois não conseguiu conectar a informação passada no enunciado da questão com o resultado encontrado. Esse tipo de erro também pode ser observado em respostas apresentadas na questão 7, na qual os alunos encontraram os zeros da função negativos, o que não poderia ocorrer, pois esses indicariam a quantidade de tratores a serem vendidos.

Figura 8 - Resposta Apresentada por A4

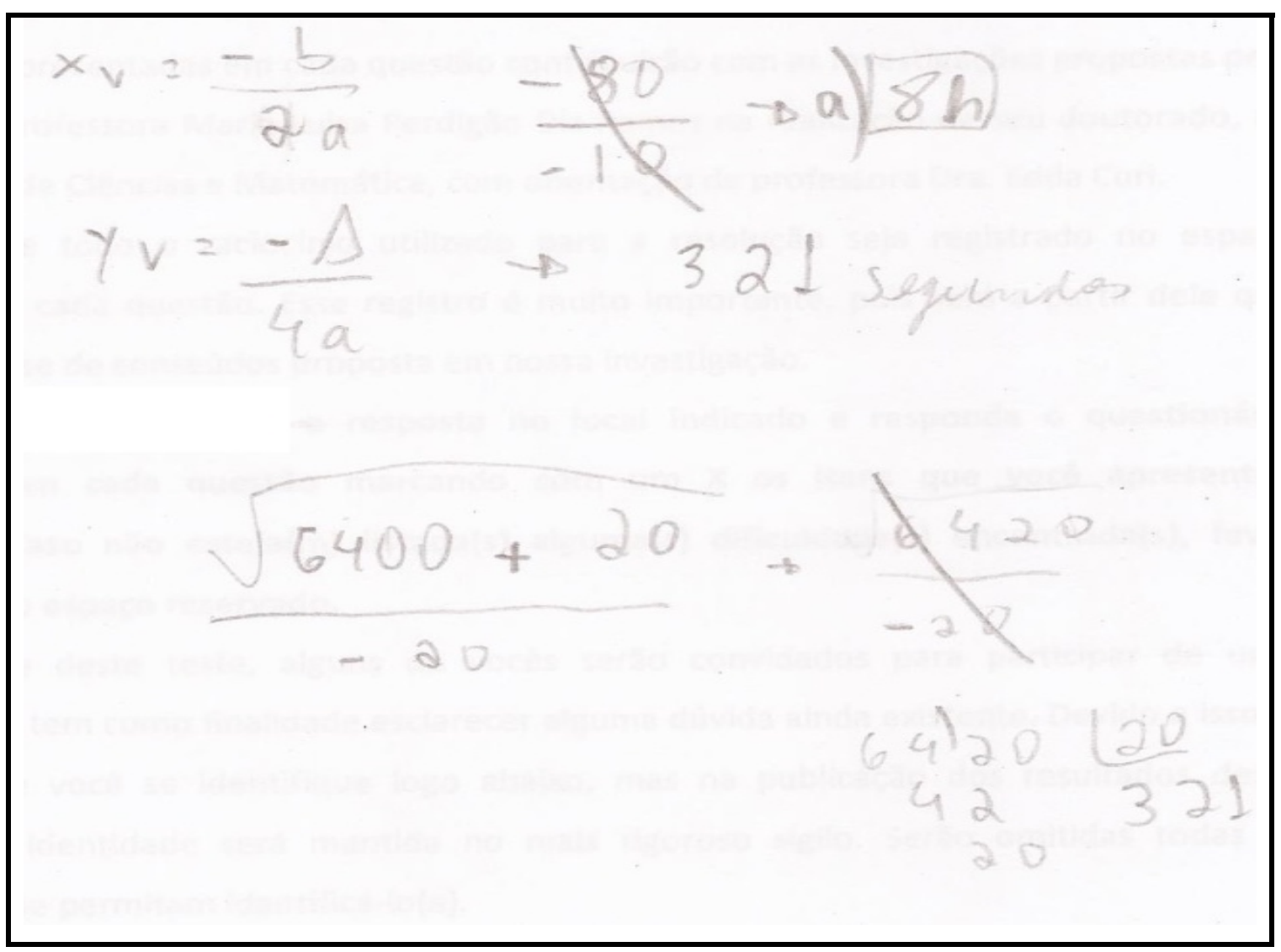

Fonte: Teste Investigativo, questão 10.

O Erro Estratégico cometido por A12 e outros três alunos está apresentado na Figura 9. A12 encontrou um dos zeros da função e o apontou como sendo o valor de t. Sem analisar a parábola descrita na questão, substituiu esse valor na função dada e encontrou de forma incorreta o valor de h. A12 utilizou-se de estratégia incorreta para encontrar o valor do tempo e com isso errou também no cálculo da altura. Além disso, ele apresentou Erro Operacional no decorrer do desenvolvimento da questão. Se não cometesse esse erro talvez percebesse que a solução apresentada estava incorreta, pois o valor encontrado referente à altura seria zero. 


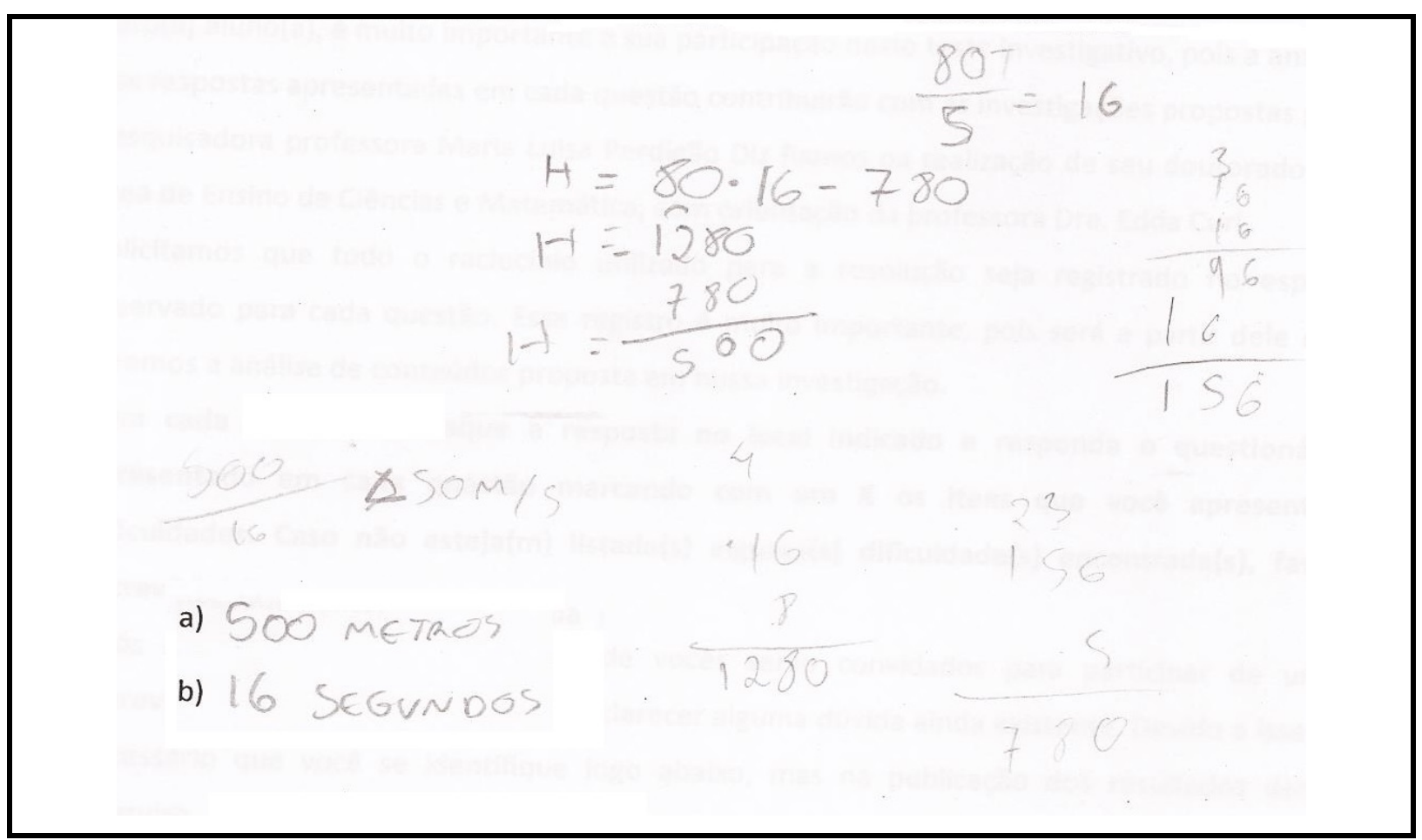

Fonte: Teste Investigativo, questão 10.

\section{Considerações finais}

Com a análise de erros é possível perceber os erros cometidos em qualquer um dos três momentos - entrada, organização e execução da informação - trazendo contribuições para o professor e para o aluno, pois segundo De La Torre (2007) "[...] os erros de execução e de organização têm a ver principalmente com as aptidões pessoais, e os erros de entrada estão muito condicionados pela atuação do professor e pelo método empregado" (p. 130).

Ao utilizarmos o MADE como uma forma de investigar os erros cometidos pelos alunos na realização dessa análise, percebemos que eles apresentaram dificuldades oriundas do Ensino Fundamental como também dificuldades em trabalhar com função polinomial do $2^{\circ}$ grau. Muitos alunos desenvolveram as questões sem levar em consideração as condições descritas em cada enunciado sobre as funções apresentadas.

Com relação aos erros categorizados como Operacionais, referentes ao conteúdo do Ensino Fundamental, foi possível perceber que os alunos encontram dificuldades em achar os zeros de uma função que possui $\mathrm{c}=0$, ou seja, uma função do tipo $\mathrm{f}(\mathrm{x})=\mathrm{ax}^{2}+\mathrm{bx}$. Um exemplo disso pode ser visto na resolução dada por A4, quando o aluno considerou c $=1$ no cálculo do $\Delta$ para esse tipo de função. Lima (2007) aponta em seu trabalho dificuldades encontradas por

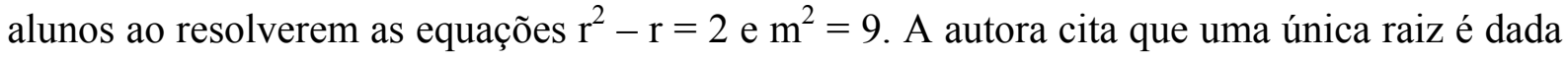


como resposta para cada equação e conclui que parece ter faltado aos alunos "motivação para buscar outra raiz.” (p. 266).

Também dentro da categoria Operacional foi possível perceber que os alunos apresentaram dificuldades em priorizar a aplicação da propriedade distributiva durante a resolução da função referente à questão 7. Dias (2004), em seu trabalho, apresenta dificuldades encontradas por alunos da $5^{\mathrm{a}}$ e da $7^{\mathrm{a}}$ séries do Ensino Fundamental e alunos do $1^{\circ}$ ano do Ensino Médio ao aplicarem a propriedade distributiva. A autora aponta que os alunos apresentaram mais dificuldades em trabalhar com a "[...] propriedade distributiva quando esta se encontra no contexto de resolução de problemas, bem como, conteúdos como soma algébrica, estudos das variáveis [...]" (p.7).

Dentro da categoria Conceitual e Lógica foi possível notar que os alunos apresentaram dificuldades em relação ao conceito de função. Pelho (2003) aborda em seu trabalho dificuldades desse tipo também apresentadas por alunos do Ensino Médio, e descreve que "a possibilidade de aprendizagem deste conceito é prejudicada por uma introdução por meio de definições diretas e formais, muitas vezes abandonando-se a noção de dependência.” (p. 8). A autora menciona que os alunos apresentam dificuldades ao relacionarem as variáveis $\mathrm{x}$ e y como variáveis independentes e dependentes, respectivamente. Essa dificuldade também pode ser percebida neste trabalho, quando os alunos não souberam relacionar as variáveis tempo e altura como sendo respectivamente as variáveis independente e dependente, gerando então problemas no desenvolvimento e na apresentação da resposta da questão 10.

Analisando os erros referentes às duas questões aqui apresentadas, percebemos que o professor deve ter o cuidado em realizar a correção dos erros da forma mais adequada possível, principalmente com relação aos erros categorizados como de Compreensão Conceitual. A retificação ou correção por repetição de tarefas faz com que esses tipos de erros se tornem sistemáticos, pois o aluno não consegue identificar as relações entre a forma correta e a forma errada. Nesse caso, Pinto (2000) aponta que, "O reconhecimento do erro é nulo, e não provoca avanço na construção do conceitual.” (p. 145). Logo, o aluno precisa da ajuda do professor para superar as dificuldades existentes.

\section{Referências}

CURY, Helena Noronha. Análise de erros: uma possibilidade de trabalho em cursos de formação inicial de professores. In: ENCONTRO NACIONAL DE EDUCAÇÃO MATEMÁTICA, 11., 2013, Curitiba. Anais... Curitiba: ENEM-PR, p. 1-15, 2013. 1 CDROM. 
DE LA TORRE, Saturnino. Aprender com os erros: o erro como estratégia de mudança. Porto Alegre: Artmed, 2007, p. 240.

DIAS, Josete Leal. A propriedade distributiva da multiplicação: uma visão diagnóstica do processo. 2004. 184f. Dissertação (Mestrado em Educação em Ciências e Matemática)Universidade Federal do Pará, Belém, 2004. Disponível em: $<$ http://repositorio.ufpa.br/jspui/bitstream/2011/1839/1/Dissertacao_PropriedadeDistributiva Multiplicacao.pdf $>$. Acesso em: 14 jan. 2014.

LEIVAS, José Carlos Pinto; CURY, Helena Noronha. Análise de erros em soluções de um problema de geometria: uma investigação com professores em formação continuada. Revista Eletrônica em Educação Matemática, Florianópolis, v.5, n.1, p. 71-83, 2010. Disponível em: $\quad<$ http://www.periodicos.ufsc.br/index.php/revemat/article/view/19811322.2010v5n1p71/21143>. Acesso em: 13 jan. 2014.

LIMA, Roseli Cristina Negrão de; BURIASCO, Regina Luzia Corio de. O conhecimento que se mostra em questões discursivas de matemática da $4^{\text {a }}$ série. IN: Buriasco, R. L. C. (Org.). Avaliação e educação matemática. Recife: SBEM, 2008.

LIMA, Rosana Nogueira de. Equações algébricas no ensino médio: uma jornada por diferentes mundos da matemática. 2007. 358 f. Tese (Doutorado em Educação Matemática)Pontifícia Universidade Católica de São Paulo, São Paulo, 2007. Disponível em: $<$ http://www.educadores.diaadia.pr.gov.br/arquivos/File/2010/artigos_teses/MATEMATICA/ Tese_Lima.pdf $>$. Acesso em: 14 jan. 2014.

LUPIÁÑEZ, José Luis. Análisis didáctico: La planificación Del aprendizaje desde uma perspectiva curricular. IN: Rico, Luis; Lupiáñez, José Luis; Molina, Marta. (Org.). Análisis didáctico em educación matemática: metodología de investigación, formación de profesores e innovación curricular. Granada, 2013.

PELHO, Edelweiss Benez Brandão. Introdução ao conceito de função: a importância da compreensão das variáveis. 2003. 146 f. Dissertação (Mestrado em Educação Matemática)Pontifícia Universidade Católica de São Paulo, São Paulo, 2003. Disponível em: $<$ http://www.sapientia.pucsp.br/tde_busca/arquivo.php?codArquivo=4686 $>$. Acesso em: 10 jan. 2014.

PINTO, Neuza Bertoni. O erro como estratégia didática. São Paulo: Papirus, 2000, p. 182.

RAMOS, Maria Luisa Perdigão Diz. Detecção, identificação e retificação: as três fases no tratamento e na correção dos erros. In: ENCONTRO NACIONAL DE EDUCAÇÃO MATEMÁTICA, 11., 2013, Curitiba. Anais... Curitiba: ENEM-PR, p. 1-14, 2013. 1 CDROM.

RAMOS, Maria Luisa Perdigão Diz; CURI, Edda. Análise de erro em avaliação de sistemas digitais: uma questão com lógica AND e flip-flop. Revista Eletrônica em Educação Matemática, Florianópolis, v.8, n.1, p. 232-247, 2013. Disponível em: $<$ https://periodicos.ufsc.br/index.php/revemat/article/view/1981-1322.2013v8n1p232/25136>. Acesso em: 13 jan. 2014. 